\title{
Research Article \\ Seismic Fragility Assessment of an Isolated Multipylon Cable-Stayed Bridge Using Shaking Table Tests
}

\author{
Yutao Pang \\ Faculty of Engineering, China University of Geosciences, Lumo Road 388, Wuhan, Hubei, China \\ Correspondence should be addressed to Yutao Pang; pangyutaoyy@gmail.com
}

Received 21 May 2017; Revised 31 July 2017; Accepted 27 August 2017; Published 12 October 2017

Academic Editor: Filippo Ubertini

Copyright (C) 2017 Yutao Pang. This is an open access article distributed under the Creative Commons Attribution License, which permits unrestricted use, distribution, and reproduction in any medium, provided the original work is properly cited.

\begin{abstract}
In recent decades, cable-stayed bridges have been widely built around the world due to the appealing aesthetics and efficient and fast mode of construction. Numerous studies have concluded that the cable-stayed bridges are sensitive to earthquakes because they possess low damping characteristics and high flexibility. Moreover, cable-stayed bridges need to warrant operability especially in the moderate-to-severe earthquakes. The provisions implemented in the seismic codes allow obtaining adequate seismic performance for the cable-stayed bridge components; nevertheless, they do not provide definite yet reliable rules to protect the bridge. To date, very few experimental tests have been carried out on the seismic fragility analysis of cable-stayed bridges which is the basis of performance-based analyses. The present paper is aimed at proposing a method to derive the seismic fragility curves of multipylon cable-stayed bridge through shake table tests. Toward this aim, a $1 / 20$ scale three-dimensional model of a $22.5 \mathrm{~m}$ cable-stayed bridge in China is constructed and tested dynamically by using the shaking table facility of Tongji University. The cable-stayed bridge contains three pylons and one side pier. The outcomes of the comprehensive shaking table tests carried out on cable-stayed bridge have been utilized to derive fragility curves based on a systemic approach.
\end{abstract}

\section{Introduction}

In recent decades, cable-stayed bridges are popular not only in China but also around the world due to appealing aesthetics, full and efficient utilization of structural materials, increasing stiffness over suspension bridges, and efficient and fast mode of construction [1]. Now, more than 400 cablestayed bridges have been constructed in China. Some of these bridges are located in high seismic zones according to the current seismic hazard map of China. From the structural dynamics point of view, cable-stayed bridges exhibit flexible and low damping behavior in which the vertical, lateral, and torsional motions are strongly coupled that raises many concerns about their behavior under environmental dynamic loads such as wind and earthquakes [2]. If a cable-stayed bridge collapses in an earthquake, it can cause tremendous loss of life and property.

Due to its complex behavior under seismic excitations, a number of previous works have been carried out to investigate the dynamic behavior of cable-stayed bridge considering either a free vibration problem or a forced vibration problem due to seismic excitations [3-5]. Many numerical methods (i.e., the time domain analysis or frequency domain spectral method) have been proposed to assess both linear and nonlinear seismic responses of cable-stayed bridges under uniform or multisupport ground motions [6-8]. Moreover, many works focused on seismic control strategy and fragility analysis for cable-stayed bridges [9-11]. With regard to the shake table test of cable-stayed bridges, few studies have proposed to investigate the seismic behavior of cable-stayed bridges. Li et al. [12] conducted the shake table studies of seismic structural systems of a Taizhou Changjiang Highway Bridge model. Wang et al. [13] investigated the transverse seismic behavior of a medium-span cable-stayed bridge model with two concrete towers. Zong et al. [14] used the $1 / 100$ scale model to study the seismic response on a multispan cable-stayed bridge scale model under multisupport excitations.

Recently, the modern earthquake engineering has focused on the performance-based assessment of new designed structures or existing buildings and bridges. Seismic fragility, which defines the damage probability as a function of seismic 


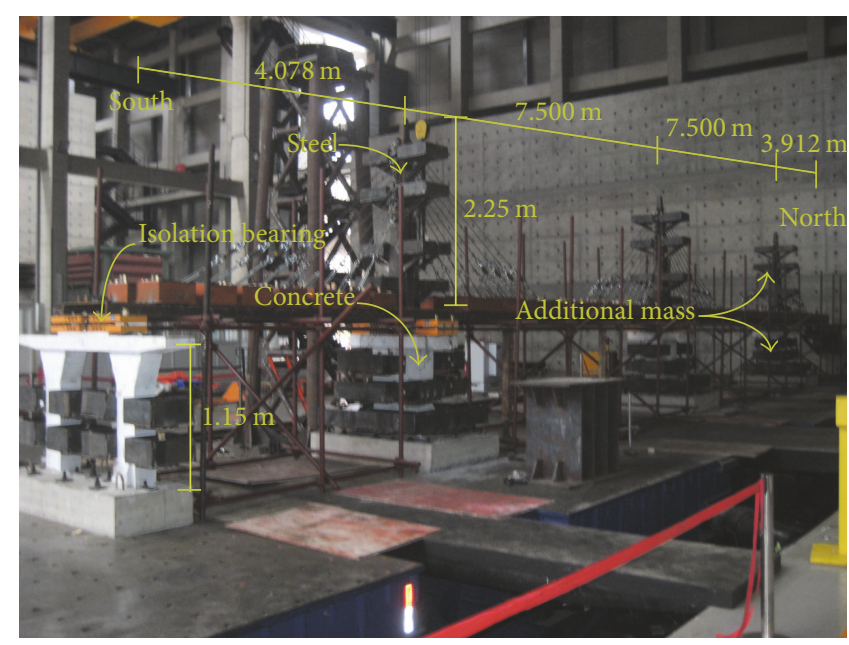

FIGURE 1: Designed shaking table test model of three-pylon cable-stayed bridge.

intensity measures, is an important part of performancebased engineering framework [15]. Three main methods are used for development of fragility functions: (1) empirical approach [16]; (2) expert opinion; and (3) analytical methods [17]. The numerical method is the main method to conduct the seismic fragility analysis of structures. With regard to the seismic fragility analysis of cable-stayed bridges, a few studies have been proposed recently to assess the seismic vulnerability of cable-stayed bridges. Casciati et al. [9] assessed the seismic reliability of a benchmark cable-stayed bridge with passive hysteretic devices using fragility curves. Barnawi and Dyke [10] developed the fragility curves of a benchmark cable-stayed bridge equipped with three response modification systems, namely, active, semiactive, and passive devices. Pang et al. [11] generated the fragility curves of a short-span cable-stayed bridge using uniform design method considering different sources of uncertainties. Wu et al. (2016) proposed a user-friendly and efficient framework for establishing the system fragility functions of medium-span concrete cable-stayed bridge based on the assumption of the serial system. Zhong et al. (2016) proposed detailed procedures to generate the component and system seismic fragility curves of a long-span cable-stayed bridge in China, including the selection of the optimal intensity measure and definition of the limit states of pylon sections. However, all these previous studies adopted numerical methods other than the experimental methods to develop the fragility curves. The cable-stayed bridges adopted in the previous papers are twopylon cable-stayed bridges, not the multipylon cable-stayed bridge, which is a rather new structure, and its seismic performances are not fully understood yet. Moreover, no studies have been initiated to analyze the seismic performance of multipylon cable-stayed bridge using the shake table testing so far.

On the basis of the above-mentioned motivations, the present paper illustrates the preliminary results of shake table tests carried out on a 1/20 scale multipylon cablestayed bridge equipped with typical isolation bearings in China. The results from previous studies are mainly based on numerical models other than the shake table tests. In the present paper, the fragility curves of different components are generated using the data from the shaking table tests. This study aims at investigating the seismic performance of multipylon cable-stayed bridge, such as cables, isolated bearings, pylon, and piers through shaking table tests. An actual cable-stayed bridge in Nanchang City in China is selected as a representative case study for the experimental assessment. Limit states were defined and identified for each components and the whole system. The recorded time histories of various components were used to develop the seismic fragility curves.

\section{Test Setup}

The shaking table tests of a multipylon cable-stayed bridge are carried out by the earthquake simulator system available at the earthquake engineering laboratory of Bridge Engineering Department of the University of Tongji, China. The system consists of four $6 \mathrm{~m} \times 4 \mathrm{~m}$ rectangle shake tables. Each table is characterized by three DOFs (longitudinal, lateral, and yaw). The maximum payload of each table is $700 \mathrm{KN}$ with a frequency ranging between 0.1 and $50 \mathrm{~Hz}$, acceleration peak equal to $1.5 \mathrm{~g}$, velocity peak equal to $1 \mathrm{~m} / \mathrm{s}$, and total displacement equal to $500 \mathrm{~mm}$. All four shake tables are utilized for the present experiment.

2.1. Scaling Method. A scale model of three-pylon cablestayed bridge was designed (Figure 1) with the purpose of simulating the seismic behavior of this type of bridge and generating the fragility curves according to the predefined limit states. The bridge model is a $1 / 20$-scale geometric model of a real six-pylon cable-stayed bridge in Nanchang City, China, based on a symmetric approach. The scaling factor is calculated based on dimensional analysis. Table 1 shows the scaling factors and corresponding dimensions and equations for the physical quantities of the shake table test. It can be seen from Table 1 that three parameters in bold are the key physical quantities, namely, length scale factor $\left(S_{l}\right)$, modulus of elasticity scale factor $\left(S_{E}\right)$, and acceleration 
TABLE 1: Control scale factors for the designed bridge model.

\begin{tabular}{|c|c|c|c|c|c|}
\hline Parameter & Length, $l$ & Acceleration, $a$ & Elastic modulus, $E$ & Displacement, $\delta$ & Strain, $\varepsilon$ \\
\hline Dimension & $\mathrm{m}$ & $\mathrm{m} / \mathrm{s}^{2}$ & $\mathrm{~N} / \mathrm{m}^{2}$ & $\mathrm{~m}$ & I \\
\hline Equation & $S_{l}$ & $S_{a}$ & $S_{E}$ & $S_{\delta}=S_{l}$ & $S_{\varepsilon}=1$ \\
\hline Scale factor & 0.05 & 2 & 0.3 & 0.05 & 1 \\
\hline Parameter & Stress, $\sigma$ & Density, $\rho$ & Mass, $m$ & Area, $S$ & Stiffness, $k$ \\
\hline Dimension & $\mathrm{N} / \mathrm{m}^{2}$ & $\mathrm{~kg} / \mathrm{m}^{3}$ & $\mathrm{~kg}$ & $\mathrm{~m}^{2}$ & $\mathrm{~N} / \mathrm{m}$ \\
\hline Equation & $S_{\sigma}=S_{E}$ & $S_{\rho}=S_{E} /\left(S_{l} S_{a}\right)$ & $S_{m}=S_{E} S_{l}^{2} / S_{a}$ & $S_{S}=S_{l}^{2}$ & $S_{k}=S_{E} S_{l}$ \\
\hline Scale factor & 0.3 & 3 & 0.000375 & 0.0025 & 0.015 \\
\hline Parameter & Time, $t$ & Bending moment, $M$ & Force, $F$ & Damping, $c$ & Velocity, $v$ \\
\hline Dimension & $\mathrm{s}$ & $\mathrm{Nm}$ & $\mathrm{N}$ & $\mathrm{Ns} / \mathrm{m}$ & $\mathrm{m} / \mathrm{s}$ \\
\hline Equation & $S_{t}=\left(S_{l} / S_{a}\right)^{0.5}$ & $S_{M}=S_{E} S_{l}^{3}$ & $S_{F}=S_{E} S_{l}^{2}$ & $S_{m}=S_{E} S_{l}{ }^{1.5} / S_{a}{ }^{0.5}$ & $S_{v}=\left(S_{a} S_{l}\right)^{0.5}$ \\
\hline Scale factor & 0.158 & 0.0000375 & 0.00075 & 0.00237 & 0.316 \\
\hline
\end{tabular}

scale factor $\left(S_{a}\right)$. Once three key physical quantities (length, time, and force) are determined, the rest quantities could be calculated by the listed equations. The reason for choosing these three quantities is that it is simple and convenient to control them during the early design stage of the tests.

$S_{l}$ is designed to be $1 / 20$ considering the limit size of the test environment, cost of fabrication, and construction of model components. The mass scale factor, $S_{m}$, which affects the scaled weight and dynamic characteristic of the bridge model greatly, is controlled by all three key quantities. In the prototype bridge, the mass of the girder is considerably large because the girder is prestressed concrete-box girder with corrugated steel web. If $S_{a}$ and $S_{E}$ are both designed as 1, the mass of the model will be too large to be acceptable and there will not be enough space to put additional mass on the model. To get a reasonable mass of the bridge model, $S_{m}$ is expected to be reduced. Given that $S_{l}$ is determined, this goal could be achieved by reducing $S_{E}$ or enlarging $S_{a}$. According to Wang et al. (2016), $S_{E}$ could be designed as small as 0.3 using microconcrete materials, yet the model mass will still be too large. Therefore, to further reduce the model mass, $S_{a}$ is fixed as 2 .

2.2. Details of Bridge Model. The prototype bridge is Nanchang Chaoyang Bridge (Wang et al. 2015) located in Jiangxi Province, China. It is a symmetrical six-pylon extra-dosed cable-stayed bridge in which the pylons are fixed to the girder and the girder is linked to the piers by bearings. The concretebox girder has a total length of $918 \mathrm{~m}$. The RC pylon is designed in herringbone pattern in the longitudinal direction with a height of $45 \mathrm{~m}$ and has nine sets of double cable plane on each side to participate in reinforcing the girder. The average height of the RC piers is $23 \mathrm{~m}$. Cable-sliding friction aseismic bearings are utilized as isolation systems in the original construction design.

The scale bridge with many scale components was built according to the above scaling method. Figure 2 shows the detailed dimension of the model components. To simulate the antisymmetric boundary condition, a special boundary device was designed at the north side of deck and manufactured as shown in Figure 3(a), to allow longitudinal displacement, while the rest of deck was supported by the so-called cable-sliding friction bearing [18] in Figure 2(b) on the four reinforced concrete (RC) piers. In order to simplify the cross section of deck, it is designed to be a streamlined, flat, thin-walled steel box as shown in Figure 3(c). The stay cables in the model are fiber core steel wire ropes. The constraints of cables were simulated by using the anchor holes at both the pylon and deck in Figure 3(d). Given that the pylons and girder are fixed, the steel is used to fabricate the three pylons to facilitate construction, also shown in Figure $3(\mathrm{~d})$. The bridge piers were constructed using the reinforced concrete with several boxes which was applied to equip the additional masses in Figure 3(e). In the bridge model, additional masses were attached to the bridge model to increase the material density of the structure and generate realistic inertial forces, which were distributed along the deck, pylons, and piers, as listed in Table 2. Additional masses of the pylons, the piers, and the girder of the side span bridge of the scale model are concentrated in several boxes, as shown in Figure 3(f).

The microconcrete was used to substitute the prototype material for the four piers, which needed to be designed as 0.3 of the prototype material. Before the shaking table tests, material tests of 9 microconcrete blocks were conducted, and the average value of tested elastic modulus was $11.3 \mathrm{GPa}$ the elastic modulus. For three pylons, the same steel was used as that of the prototype, fluctuating around the adopted scale factor (0.3) of elastic modulus of the prototype material. The actual yield and ultimate strength of the steel bars used as longitudinal reinforcements are 400 and $525 \mathrm{MPa}$, respectively. Those of the galvanized wires used as reinforcement stirrups are 330 and $415 \mathrm{MPa}$, respectively.

2.3. Input and Testing Protocol. To investigate the seismic behavior of the multipylon cable-stayed bridge, a suite of four recorded ground motions and four artificial ground motions were used as input uniformly for longitudinal shakings (Figure 4). The four as-recorded ground motions were selected based on the following criteria: (a) magnitude is between 5.5 and 8 and (b) Vs30 ranges from 250 to $500 \mathrm{~m} / \mathrm{s}$ to represent the soil class II in the Chinses guideline for bridge [19]. The recorded ground motions are the 1940 Imperial Valley 
TABLE 2: Additional masses of different parts.

\begin{tabular}{lcccc}
\hline Part & Mass of a single block $(\mathrm{kg})$ & Count & Steel box $(\mathrm{kg})$ & Total mass $(\mathrm{kg})$ \\
\hline Deck & 7.3 & 2304 & 2880 & 19699.2 \\
Pylons & 7.3 & 336 & 780 & 3232.8 \\
Piers & 5 & 1340 & 1828 & 8528 \\
\hline
\end{tabular}

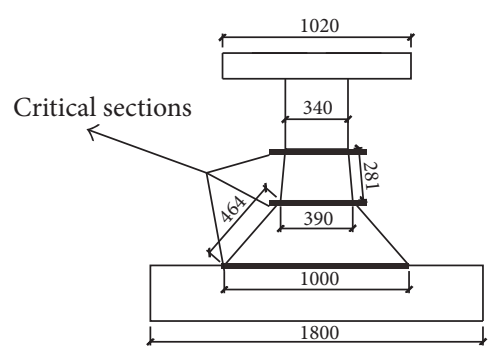

(a) Main pier

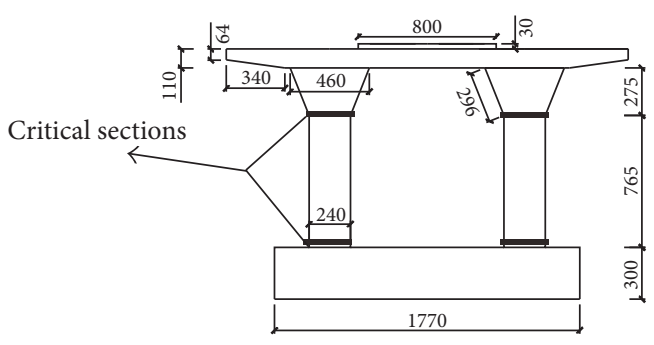

(c) Side pier

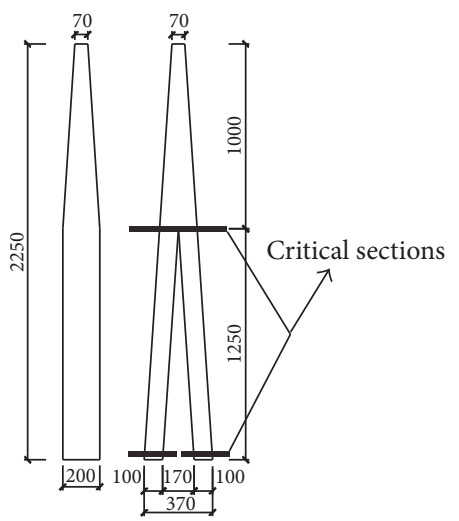

(b) Pylon

Figure 2: Detailed dimension of the scale components.

earthquake (Station El Centro Array \#9), the 1999 Chi-Chi earthquake (Station TCU052), the 1980 Mammoth Lakes earthquake (Station Convict Creek 90), and the 1986 Chalfant Valley earthquake (Station Benton 270). It should be noted that because the scaling method of ground motions was used in the shaking table tests, the compatibility with the target spectrum [19] was not done for recorded ground motions. The artificial ground motion includes two Nanchang waves and two ETA waves. The Nanchang waves were generated using the design target spectrum and provided by the bridge site seismic evaluation report ("Seismic Safety Evaluation Report for Nanchang Chaoyang Bridge Construction Site," Earthquake Disaster Mitigation Engineering Research Institute of Jiangxi Province, unpublished report, 2012). The two ETA waves were also generated based on the design target spectrum using the algorithm proposed by Hariri-Ardebili et al. [20]. Figure 5 shows the spectra of 8 ground motions considered in this study.

Each ground motion wave was applied to the bridge model using scaling method in the longitudinal direction. The PGA of each wave varies from 0.05 to $0.8 \mathrm{~g}$. Before the application of each accelerogram, a white noise wave was used to monitor the change in the dynamic characteristics of the bridge models. Six cases with different PGA, namely,
$0.05 \mathrm{~g}, 0.1 \mathrm{~g}, 0.2 \mathrm{~g}, 0.4 \mathrm{~g}, 0.6 \mathrm{~g}$, and $0.8 \mathrm{~g}$, for each wave were considered.

Recorded demands of pier, pylon, bearing, and girder were measured by 215 transducers collecting data from the bridge model with a sampling frequency of $256 \mathrm{~Hz}$ using NI data acquisition system in Figure 6. The displacements and acceleration for the decks, pylons, and piers were measured by 37 displacement transducers and 48 accelerometers, respectively. The strains in the longitudinal and transverse reinforcement at critical sections of the pylons and piers were measured by 128 strain gauges. The critical sections are the bottom sections of the piers and pylons and the pylon sections just above the lower cross beams.

2.4. Damage Definition. In seismic fragility analysis, the damage states of various components are very important due to the reason that the fragility functions are associated with the component capacity. Thus, a damage scheme is defined in this study so that the visual damage inspected in the shaking table tests can be relevant with one damage state. For example, the minor crack of concrete at the base of the pier, which was observed in the tests, can be related to slight damage state of piers. In order to prevent the shake table devices to be damaged by the collapse of the bridge model, only two 


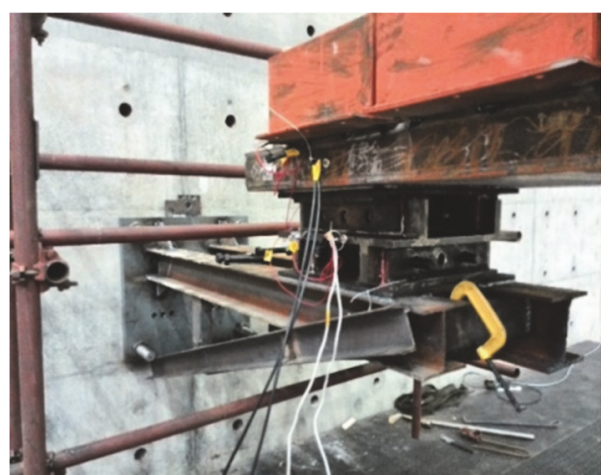

(a) Boundary device

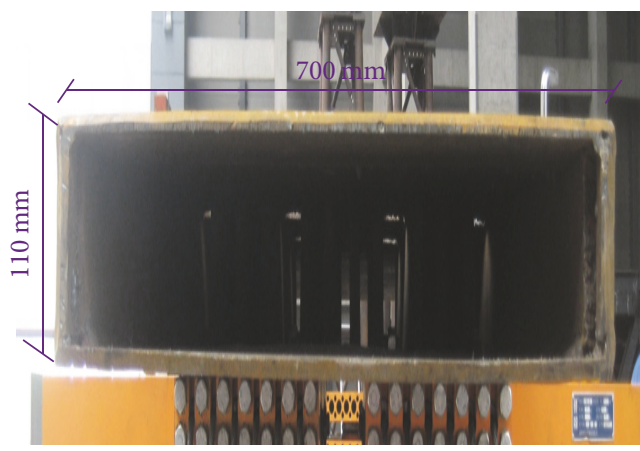

(c) Box-section girder

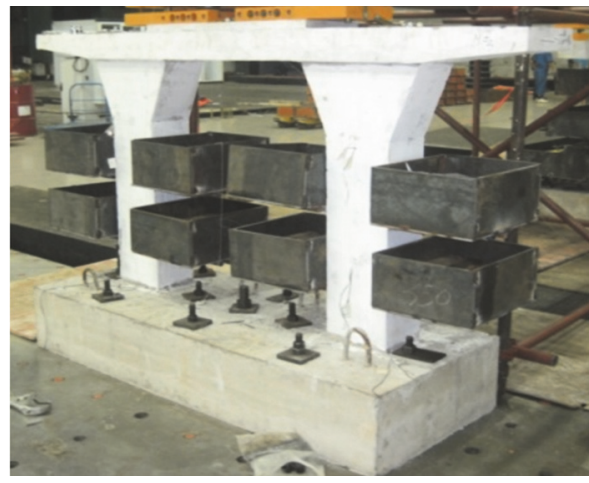

(e) RC piers

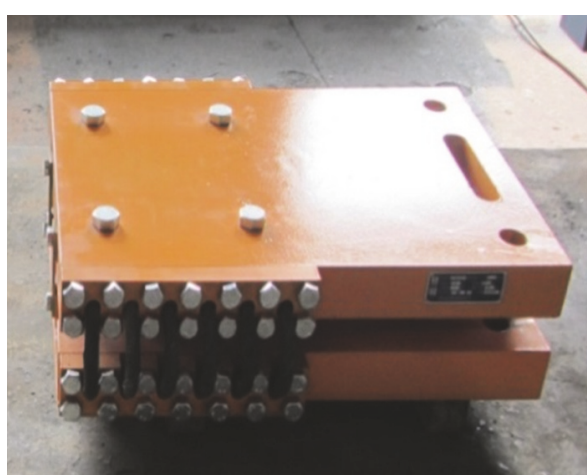

(b) Isolation system

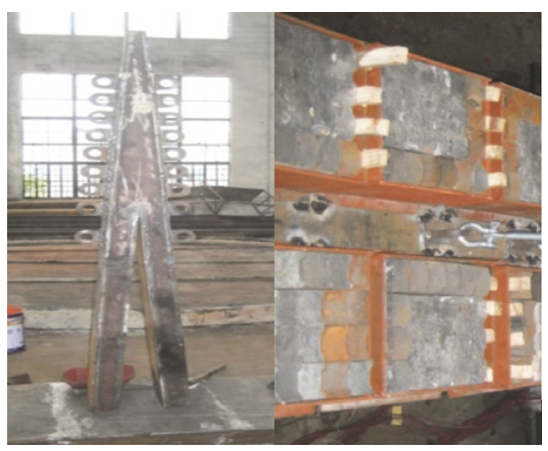

(d) Isolation system

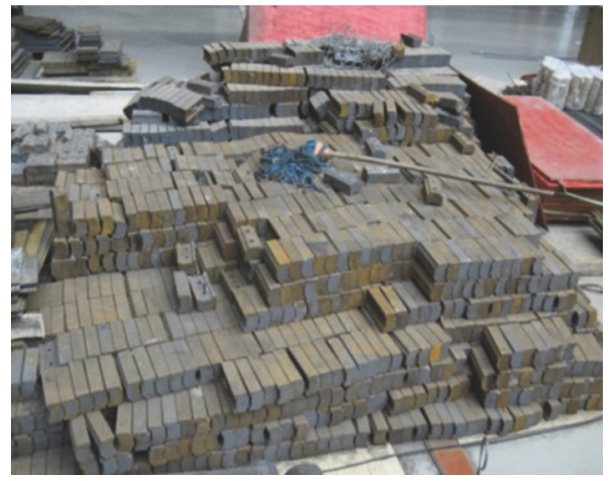

(f) Additional masses

FIgURE 3: Detailed information of bridge model.

damage states of components are considered and defined, that is, damage state 1 (DS1) and damage state 2 (DS2). The DS1 implies the initial or slight damage of each component comparing to their original conditions. The DS2 means the moderate damage of components which could cause significant change on dynamic characteristic of the whole bridge. The damage of components in the bridge was usually defined based on the seismic demands or visual damage, such as the concrete crack or the residual displacement of components, which can be seen by the inspection after each test. The inspected visual damage in each component of bridge can be then related to one specific damage state which is defined in Table 3. It should be noted that, after each test, if the bridge had residual displacement or minor crack, the bridge should be relocated or repaired to its original state.
In Table 3, the broken anchors of cables were defined as the moderate damage (DS2). The slight damage of cables can be referred to the yield forces of cables. However, due to the limited number of transducers, the cable forces were not measured in the test. Thus, cable damage at DS1 was undefined. The damage of the pylon was defined based on the drift ratio of top pylon. In the design practice of cablestayed bridge, the capacity drift ratio for pylon is usually among $3 \%-5 \%$. For the cable-stayed bridge considered in this study, the pylon height was relatively short. Thus, $0.3 \%$ and $1.5 \%$ were assumed for the DS1 and DS2, respectively. For bridge piers, the DS1 damage of piers was defined by the minor crack of concrete. The top acceleration of piers was used for DS2. The value was calculated through the yield shear force $(11,920 \mathrm{kN})$ of the original base section of the 

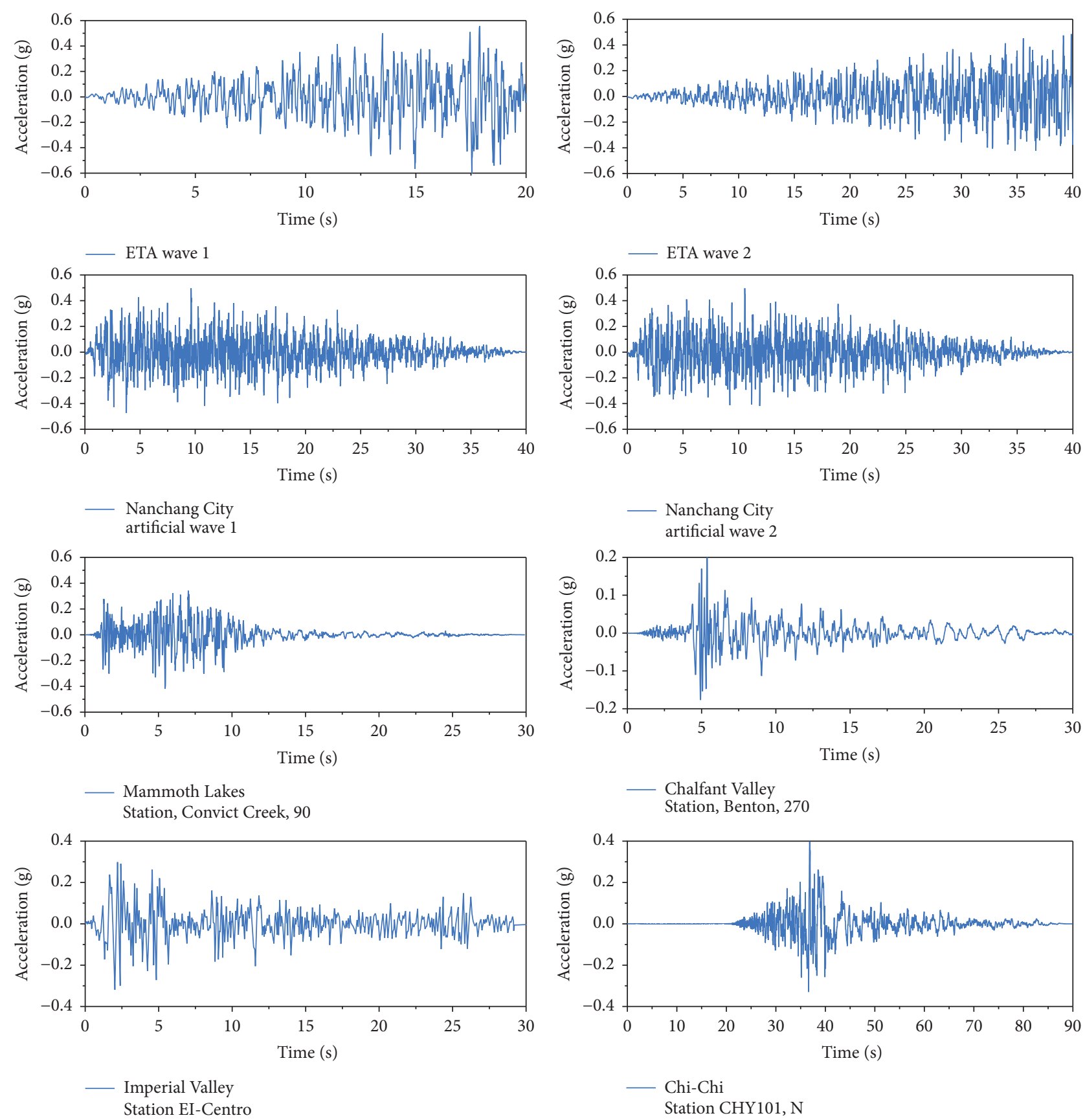

FIGURE 4: A suite of 8 ground motions for longitudinal shakings.

pier. The damage of deck and bearing damage were defined only for DS2. This is because both of them are the accessory components. The damage of accessory components may not lead to significant effect of globe system, which means that it can be replaced or relocated after the earthquakes. In this study, the cable-sliding friction aseismic bearings with $1 \mathrm{~cm}$ free distance were used as isolation bearing. After $1 \mathrm{~cm}$ sliding distance, the cable in the bearing could begin to restrict the displacement of deck. Thus, the peak displacement $1 \mathrm{~cm}$ was used as the value of DS2. The uplift of top slab was also observed in the test, so it was also used as the criterion of bearing damage at DS2. Moreover, the residual displacement was used to define the damage of the deck. The value was assumed to be $0.7 \mathrm{~cm}$ considering its influence on the relocation after the tests.

\section{Results and Discussion}

3.1. Dynamic Identification. The damping ratios corresponding to the fundamental frequency from the shake table tests were identified using the results of the white noise excitations. The damping ratios were obtained by the half-power bandwidth method. For the bridge model used in this paper, damping ratio of $2.45 \%$ was obtained. Both white noises and 


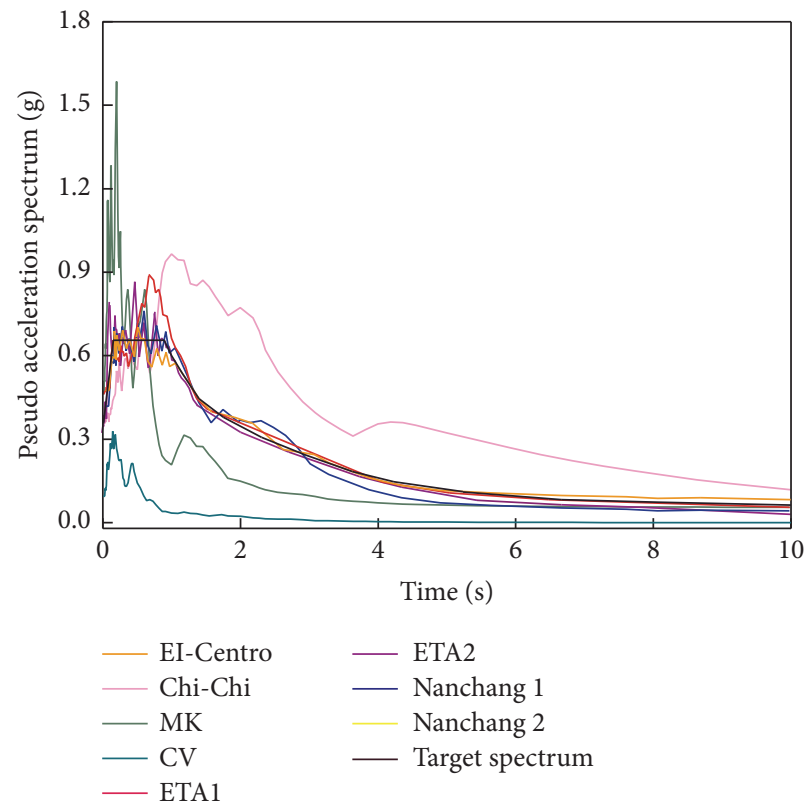

FIGURE 5: Response spectra of scaled ground motion (damping ratio 5\%).

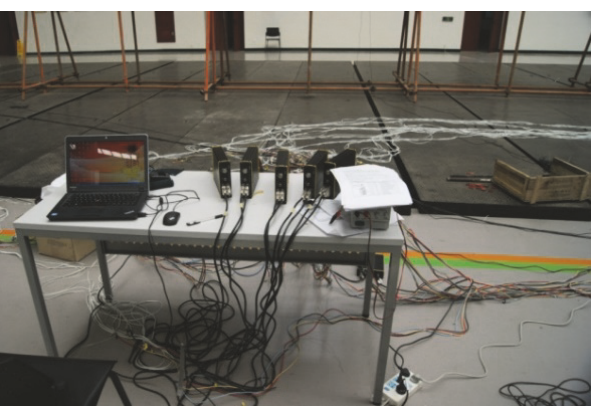

(a)

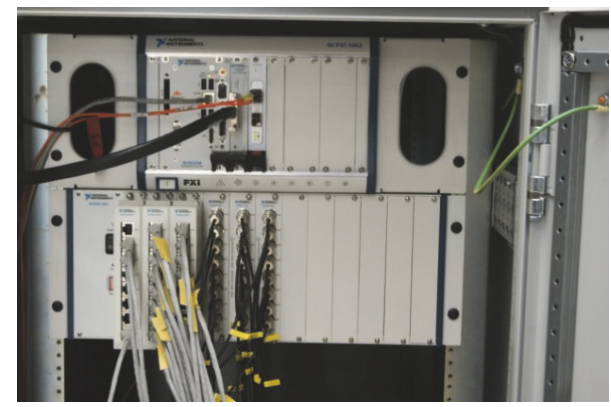

(b)

FIGURE 6: NI data acquisition system: (a) strain acquisition system and (b) displacement and acceleration acquisition system.

sweep tests were performed in order to dynamically identify the dynamic characteristic of multipylon cable-stayed bridge. The transfer function has been adopted to evaluate the natural frequency of the different components. In the transfer curve method, the acceleration time-history recorded on the deck is used to evaluate the natural frequency of the bridge. The vibration period was equal to $0.21 \mathrm{~s}$.

3.2. Test Results. Earthquake shakings are performed according to the test program described in Section 2.2. Due to the fact that the scale model of bridge was put upon four different shake tables, these four shake tables need to move simultaneously during the shaking table tests. Therefore, after each test, the compatibility of the shaking acceleration from four shaking tables is checked and verified. Figure 7 shows the compatibility verification for four shake tables when conducting the shaking test using artificial ground motion (agl) with PGA $0.4 \mathrm{~g}$.

In the shaking table tests, time-history responses of four components in the longitudinal direction of multispan cable-stayed bridge, namely, pier acceleration, top pylon displacement, bearing displacement, and residual displacement of girder, are recorded. During the tests, the videos are recorded in order to confirm the results of the "visual" damage detection. Figure 8 provides the time-history responses of four components (pier, pylon, bearing, and girder) at the EI-Centro wave $(0.8 \mathrm{~g})$. It can be seen from Figure 8 that different bridge components have different maximum seismic responses. It is also evident from Figure 8 that bearing displacement and girder displacement have similar time to obtain maximum responses. If there is a large bearing displacement response, a momentary increase in pier top acceleration and pylon displacement occurs. In the EI-Centro wave $(0.8 \mathrm{~g})$, the momentary increase occurs at around $4 \mathrm{~s}$.

Recorded maximum demands of four components, namely, pier acceleration, top pylon displacement, bearing displacement, and residual displacement of girder, are reordered. Figure 9 shows the maximum responses of four components. In Figure 9, the pier amplification which is defined as the ratio between the peak pier acceleration and 
TABLE 3: Damage scheme for the correlation of the visual damage to the damage state.

\begin{tabular}{|c|c|c|c|}
\hline \multirow{2}{*}{ Components } & \multirow{2}{*}{ Damage typology } & Damage state 1 (DS1) & Damage state 2 (DS2) \\
\hline & & Slight damage & Moderate damage \\
\hline Cable & - & N/A & Broken anchor \\
\hline Pylon & Drift & Drift larger than $0.3 \%$ & Drift larger than $1.5 \%$ \\
\hline Pier & Crack or steel yield & $\begin{array}{c}\text { Minor crack of } \\
\text { concrete }\end{array}$ & $\begin{array}{c}\text { Pier acceleration } \\
\text { larger than } 1.2(\mathrm{~g})\end{array}$ \\
\hline Bearing & Displacement & N/A & $\begin{array}{l}\text { Peak displacement } \\
\text { larger than } 1 \mathrm{~cm} \text { or } \\
\text { uplift of top slab }\end{array}$ \\
\hline Deck & $\begin{array}{c}\text { Residual } \\
\text { displacement }\end{array}$ & $\mathrm{N} / \mathrm{A}$ & $\begin{array}{c}\text { Residual } \\
\text { displacement larger } \\
\text { than } 0.7 \mathrm{~cm}\end{array}$ \\
\hline
\end{tabular}

Note. N/A means that this type of damage state is not defined.

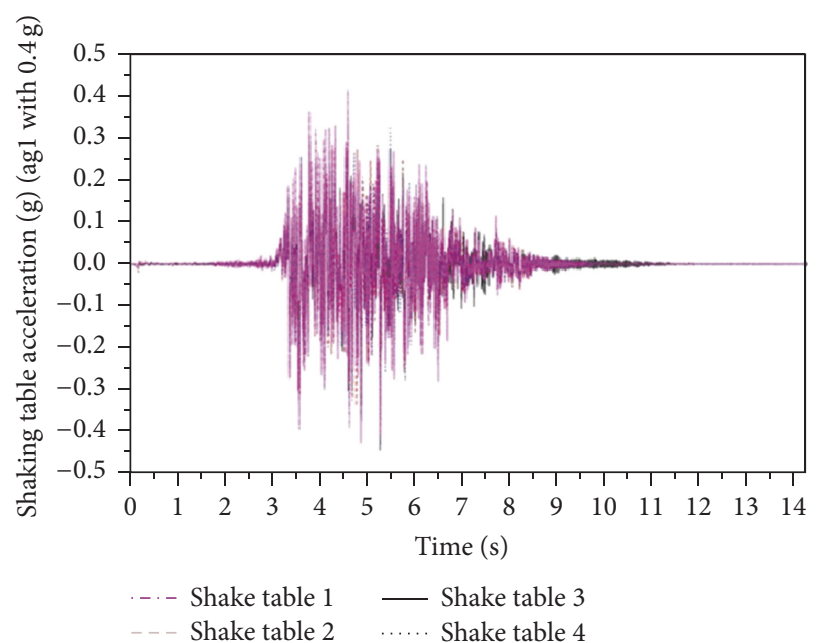

FIGURE 7: Compatibility verification for acceleration of four shake tables.

the peak shake table acceleration is plotted versus the peak shake table acceleration. The pylon drift is defined as the ratio between the top pylon displacement and pylon height above the deck. From Figure 9(a), it can thus be seen that the pier amplification is in the range between 1 and 3 for low intensity shakings, that is, peak shake table acceleration less than $0.3 \mathrm{~g}$. As the shake table input intensity increases, the general trends of pier amplification increase. From Figures 9(b) and 9(c), it can be seen that the pylon drift and bearing displacement for the artificial ground motions are larger than those for the as-reordered ground motions, except for the Chi-Chi ground motions due to high magnitude of Chi-Chi earthquake. Indeed, for the pier amplification, the values for Chi-Chi ground motion are larger than other earthquakes. From Figure 9(d), it can be seen that residual displacements of deck for different ground motions are different. In general trends, in the low intensity shaking, the residual displacement of deck is relatively small comparing to the displacement in the moderate-to-high intensity shaking.

3.3. Fragility Curve Generation. The ground motions used in Section 2.2 are unidirectional. Thus, it is assumed in the present study that the simultaneous effects of the two orthogonal motions are neglected. In order to correlate the selected EDPs (e.g., pier acceleration, top pylon displacement, bearing displacement, and residual displacement of girder) to the two defined damage states, the results of shaking table tests under 8 ground motions using IDA method are combined in order to generate regression analysis between EDPs and PGA. Table 4 shows the results from the regression analysis. It should be noted that the damage states of cable forces are omitted due to the reason that the cables have no damage phenomena during shaking table tests.

According to the data in Table 4, the fragility curves are evaluated based on the procedures. The fragility parameters are computed as follows:

$$
\begin{aligned}
& s_{m}=\exp \left(\frac{1}{n} \sum_{i=1}^{n} \operatorname{In} e_{i}\right) \\
& \beta_{m}=\sqrt{\frac{1}{n-1} \sum_{i=1}^{n}\left(\operatorname{In}\left(\frac{e_{i}}{s_{m}}\right)\right)^{2}+\beta_{u}^{2}},
\end{aligned}
$$

where $n$ is the number of ground motions, $e_{i}$ is the EDP of four components at which a given damage state occurs in 


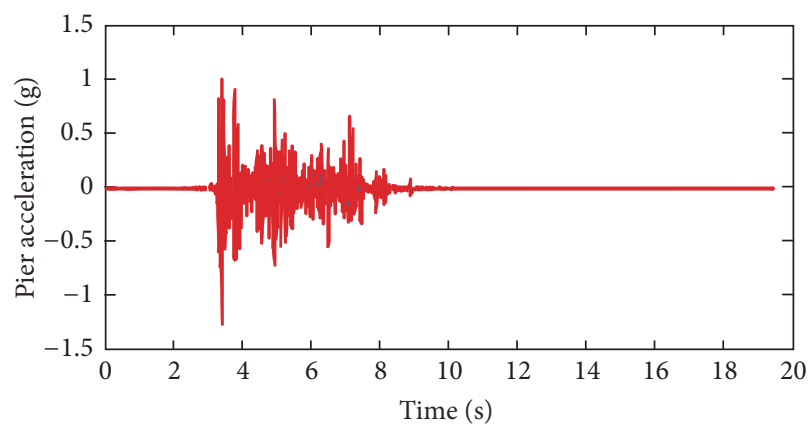

(a)

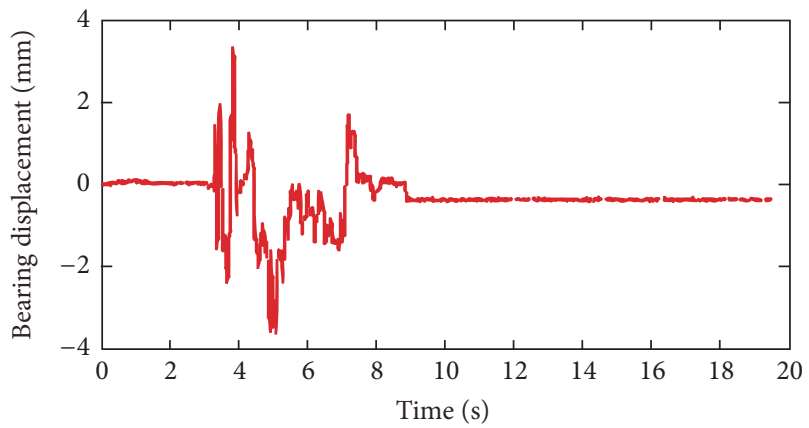

(c)

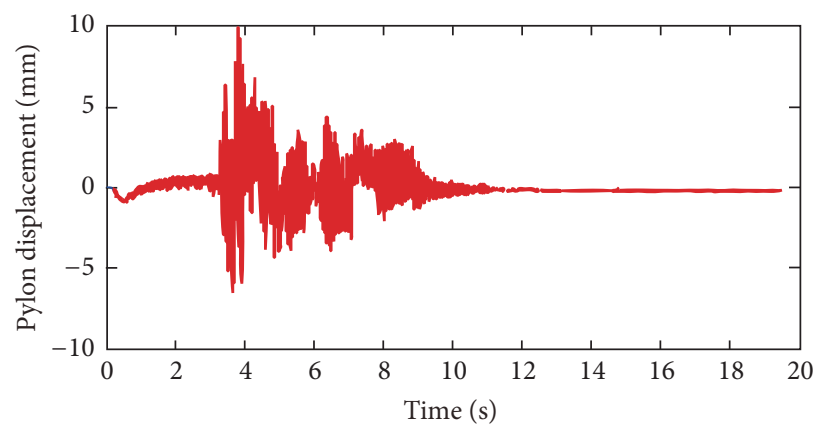

(b)

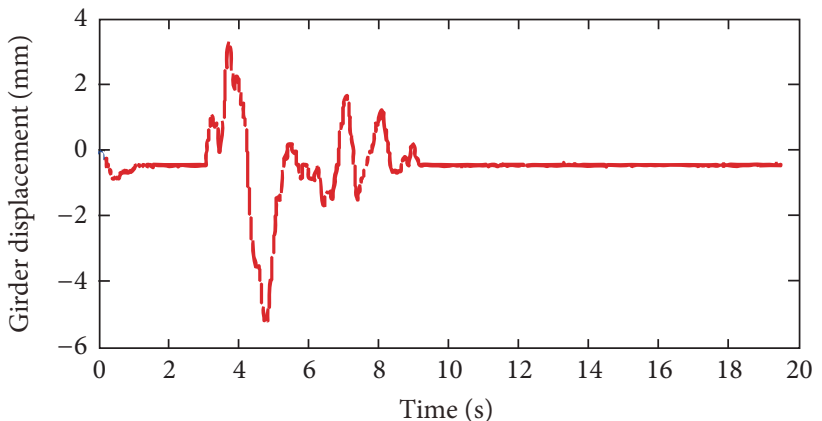

(d)

FIGURE 8: Time-history responses of four components: (a) pier acceleration; (b) pylon displacement; (c) bearing displacement; and (d) girder displacement for EI-Centro wave $(0.8 \mathrm{~g})$.

TABLE 4: Results from the regression analysis.

\begin{tabular}{lccc}
\hline \multirow{2}{*}{ Components } & \multicolumn{2}{c}{ Log-regression parameters } & Log-standard deviation \\
\hline Pier & $a$ & $b$ & 0.13 \\
Pylon & 1.19 & 1.03 & 0.41 \\
Bearing & 0.98 & 0.51 & 0.45 \\
Deck & 1.37 & 3.57 & 0.95 \\
\hline
\end{tabular}

the test model, and $\beta_{u}$ equals 0.25 , taking into account the capacity variation when the number of the tested specimens is less than 5 . The fragility curves that fit the experimental data are clearly evidenced with respect to the ones with the larger dispersion in Figure 10. The latter also takes into account the logarithmic standard deviation $\beta_{u}$.

In this paper, the randomness of ground motions is taken into account to generate the fragility curves of components of multispan cable-stayed bridge. Firstly, empirical probability is estimated by the inspection observations during the shaking table test. Then, the fitted fragility curves are developed based on the Lilliefors goodness-of-fit test [21] with a 5\% confidence level. Figure 10 shows the results of generated fragility curves of four components. As shown in Figure 8, the fitted fragility curves are compared well with the empirical probability.

\section{Conclusions}

The research study presented in this paper is motivated by the needs to investigate the seismic performance of multispan cable-stayed bridge. The preliminary results of shake table tests on a 1/20 scale model equipped with typical isolated bearings are discussed. A real multispan cablestayed bridge is selected as representative layout for the experimental seismic performance assessment. A suite of 8 ground motions is used with six different PGA levels for seismic input. A total of 48 shakings are performed during the whole test campaign. After the test, the following is concluded:

(1) The pier amplification is in the range between 1 and 3 for low intensity shakings, that is, peak shake table acceleration less than $0.3 \mathrm{~g}$. As the shake table input intensity increases, the general trends of pier amplification increase.

(2) In general, the pylon drift and bearing displacement for the artificial ground motions are larger than those for the as-reordered ground motions, except for the Chi-Chi ground motions. In the low intensity 


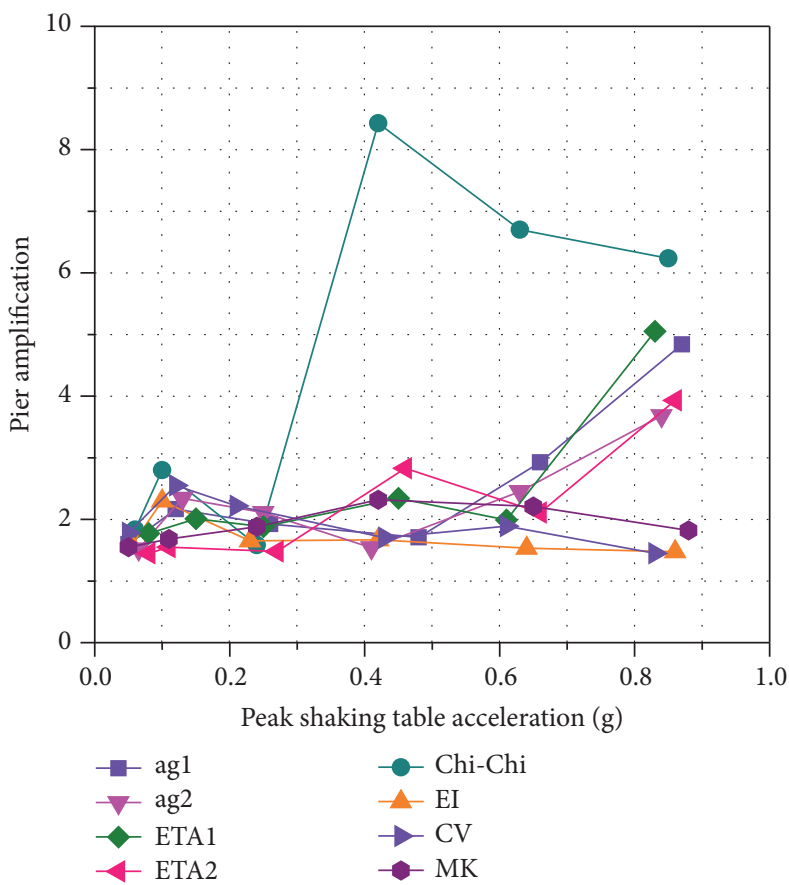

(a)

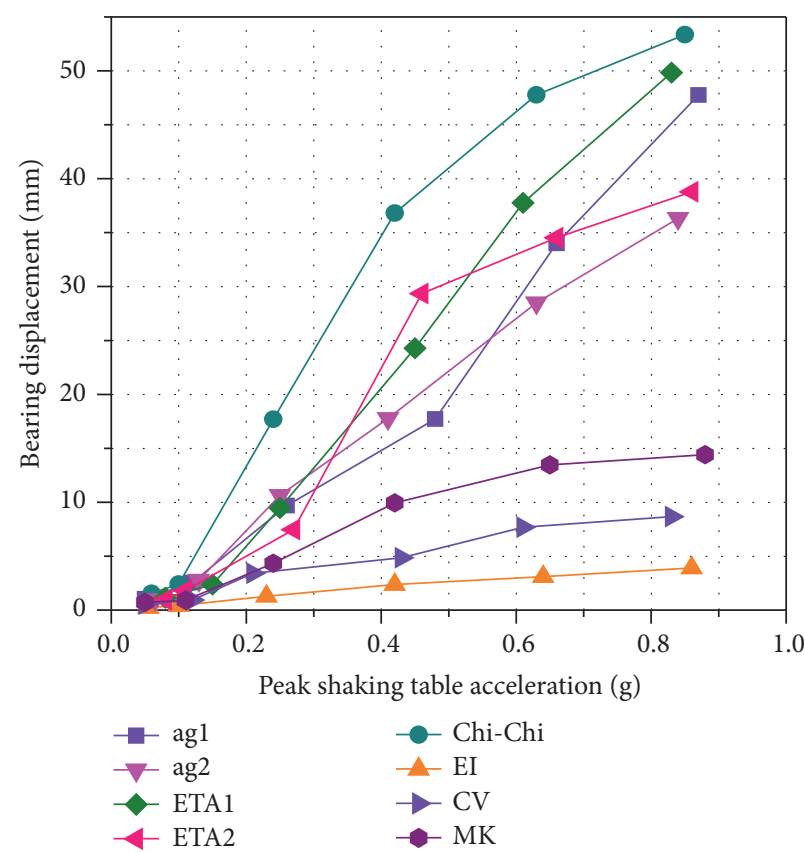

(c)

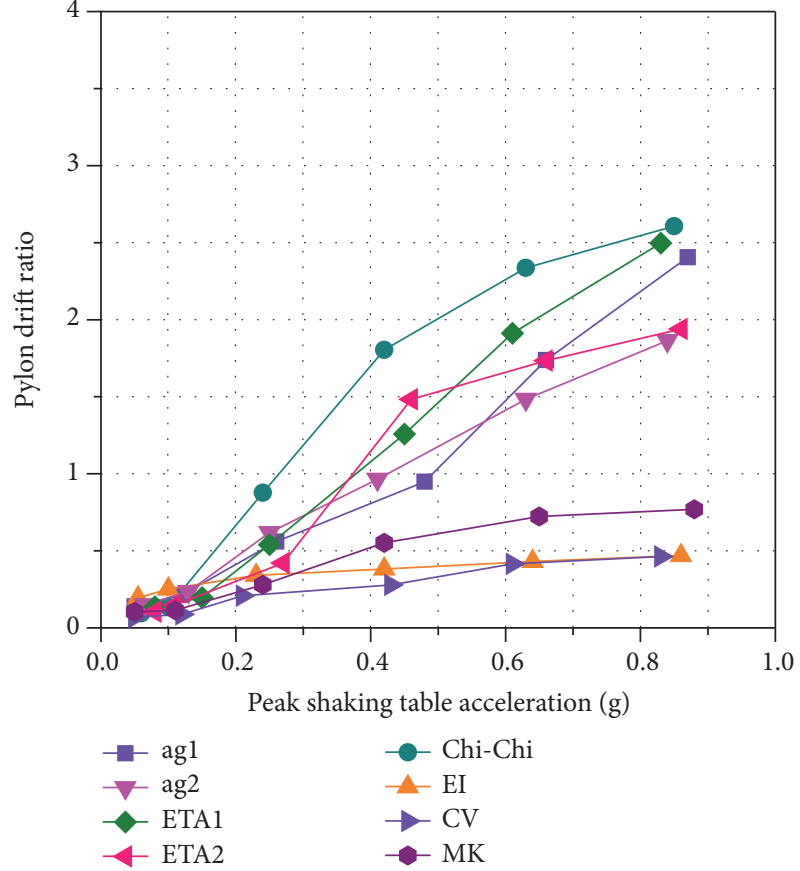

(b)

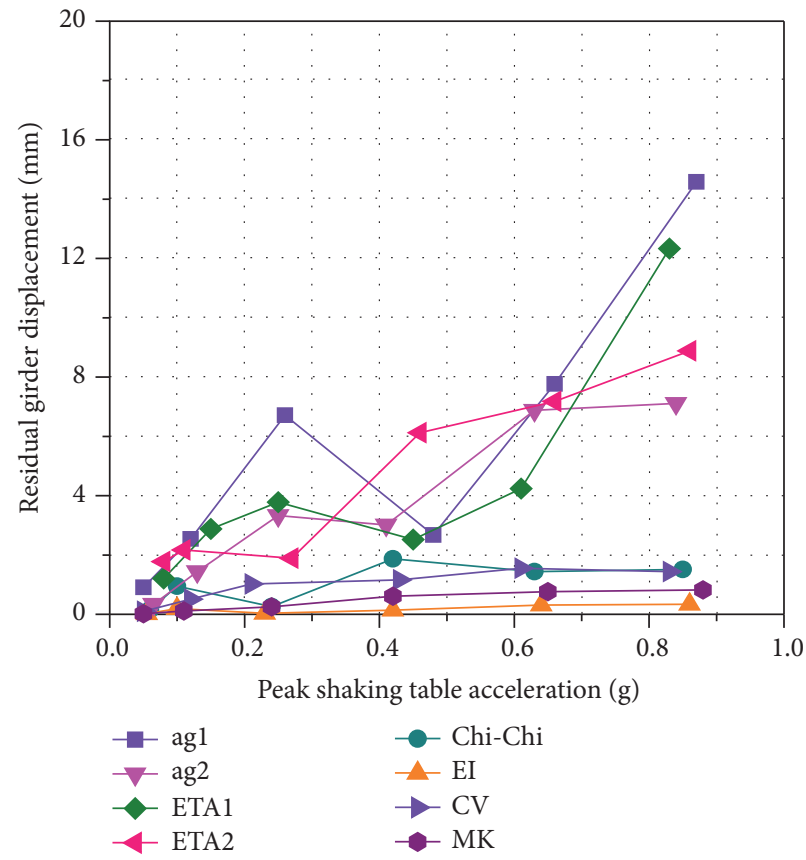

(d)

Figure 9: Maximum responses of four components: (a) pier acceleration; (b) pylon drift; (c) bearing displacement; and (d) deck displacement.

shaking, the residual displacement of deck is relatively small comparing to the displacement in the moderate-to-high intensity shaking.

(3) Empirical probability is estimated in this paper by the inspection observations during the shaking table test. The fitted fragility curves are developed based on the
Lilliefors goodness-of-fit test with a 5\% confidence level, which are compared well with the empirical probability.

\section{Conflicts of Interest}

The author declares no conflicts of interest. 


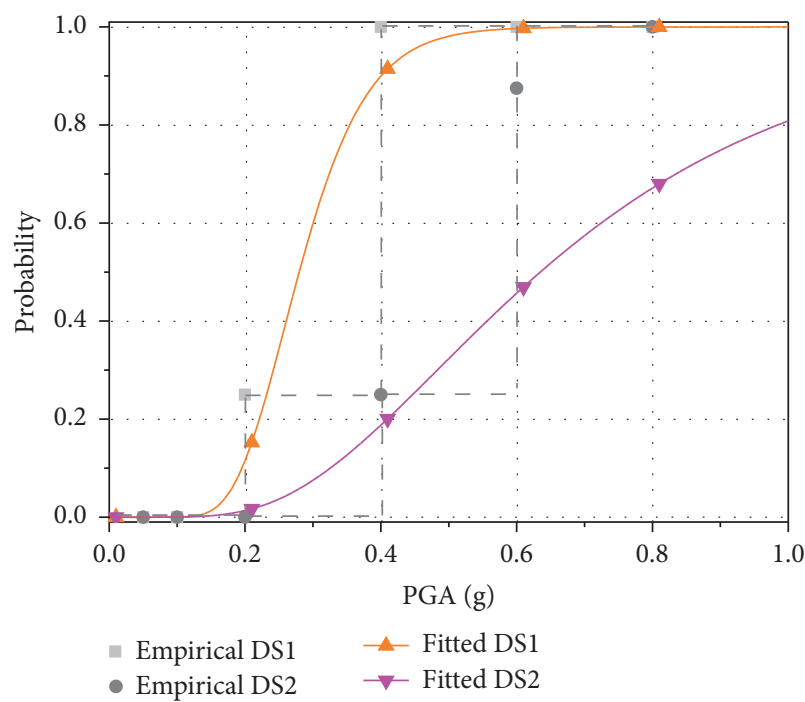

(a)

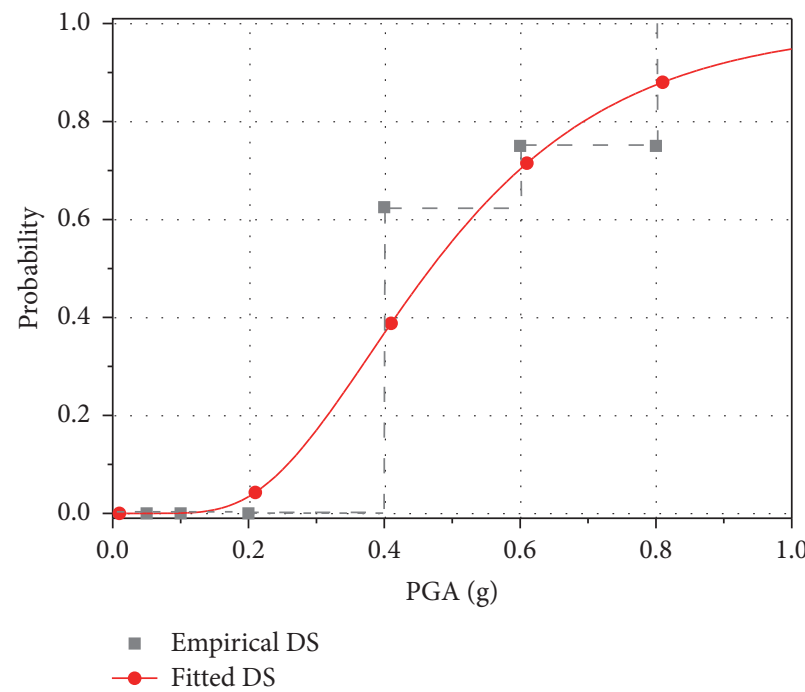

(c)

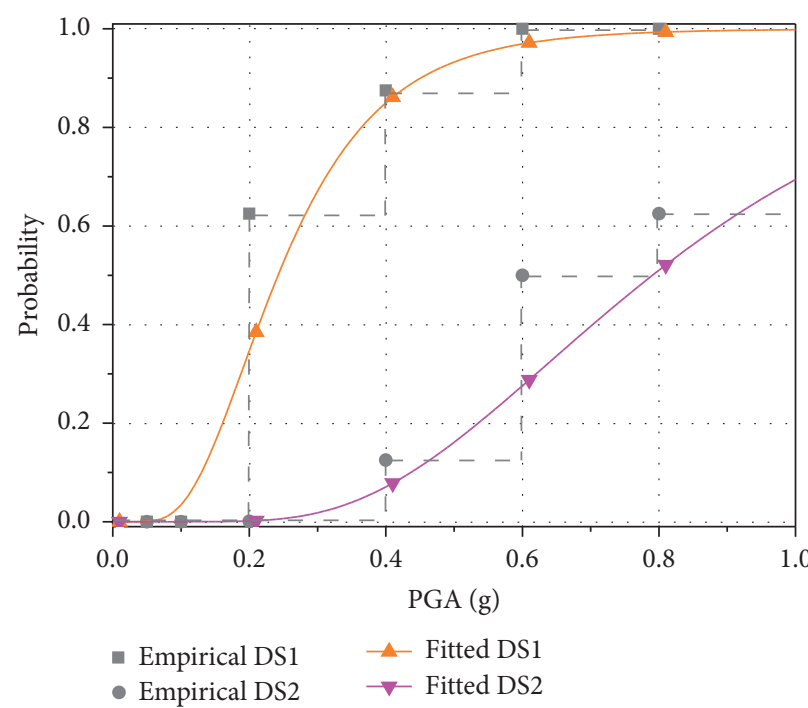

(b)

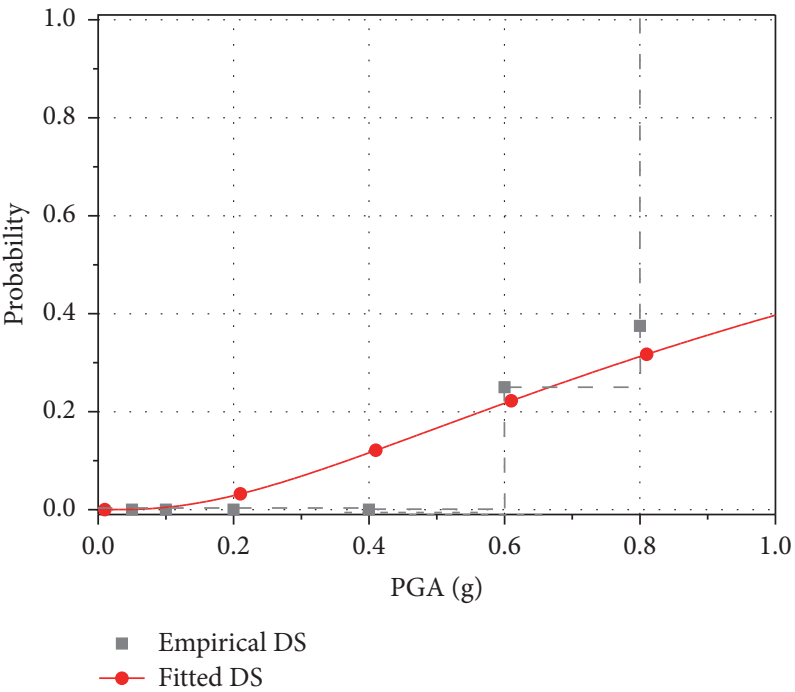

(d)

FiguRE 10: Generated fragility curves of four components: (a) pier acceleration; (b) pylon drift; (c) bearing displacement; and (d) deck displacement.

\section{Acknowledgments}

This research is supported by the Fundamental Research Funds for the Central Universities, China University of Geosciences (Wuhan) under Grant no. G1323521673, China Postdoctoral Science Foundation under Grant no. 2016M592407, and the Natural Science Foundation of China under Grant no. 51708527.

\section{References}

[1] W.-X. Ren and M. Obata, "Elastic-plastic seismic behavior of long span cable-stayed bridges," Journal of Bridge Engineering, vol. 4, no. 3, pp. 194-203, 1999.

[2] B. M. Pacheco, Y. Fujino, and A. Sulekh, "Estimation curve for modal damping in stay cables with viscous damper," Journal of
Structural Engineering (United States), vol. 119, no. 6, pp. 19611979, 1993.

[3] J. C. Wilson and T. Liu, "Ambient vibration measurements on a cable-stayed bridge," Earthquake Engineering \& Structural Dynamics, vol. 20, no. 8, pp. 723-747, 1991.

[4] S. J. Dyke, J. M. Caicedo, G. Turan, L. A. Bergman, and S. Hague, "Phase I benchmark control problem for seismic response of cable-stayed bridges," Journal of Structural Engineering, vol. 129, no. 7, pp. 857-872, 2003.

[5] M. Domaneschi and L. Martinelli, "Performance comparison of passive control schemes for the numerically improved ASCE cable-stayed bridge model," Earthquake and Structures, vol. 3, no. 2, pp. 181-201, 2012.

[6] A. S. Nazmy and A. M. Abdel-Ghaffar, "Non-linear earthquakeresponse analysis of long-span cable-stayed bridges: theory," Earthquake Engineering \& Structural Dynamics, vol. 19, no. 1, pp. 45-62, 1990. 
[7] A. S. Nazmy and A. M. Abdel-Ghaffar, "Effects of ground motion spatial variability on the response of cable-stayed bridges," Earthquake Engineering \& Structural Dynamics, vol. 21, no. 1, pp. 1-20, 1992.

[8] H.-E. M. Ali, "Seismic passive control of cable-stayed bridges," Shock and Vibration, vol. 2, no. 4, pp. 259-272, 1995.

[9] F. Casciati, G. P. Cimellaro, and M. Domaneschi, "Seismic reliability of a cable-stayed bridge retrofitted with hysteretic devices," Computers and Structures, vol. 86, no. 17, pp. 1769-1781, 2008.

[10] W. T. Barnawi and S. J. Dyke, "Seismic fragility relationships of a cable-stayed bridge equipped with response modification systems," Journal of Bridge Engineering, vol. 19, no. 8, Article ID A4013003, 2014.

[11] Y. Pang, X. Wu, G. Shen, and W. Yuan, "Seismic fragility analysis of cable-stayed bridges considering different sources of uncertainties," Journal of Bridge Engineering, vol. 19, no. 4, Article ID 04013015, 2014.

[12] J. Li, J. Yan, T. Peng, and L. Han, "Shake table studies of seismic structural systems of a taizhou changjiang highway bridge model," Journal of Bridge Engineering, vol. 20, no. 3, Article ID 04014065, 2015.

[13] R. Wang, Y. Xu, and J. Li, "Transverse seismic behavior studies of a medium span cable-stayed bridge model with two concrete towers," Journal of Earthquake Engineering, vol. 21, no. 1, pp. 151168, 2017.

[14] Z.-H. Zong, R. Zhou, X.-Y. Huang, and Z.-H. Xia, "Seismic response study on a multi-span cable-stayed bridge scale model under multi-support excitations. Part I: shaking table tests," Journal of Zhejiang University SCIENCE A, vol. 15, no. 5, pp. 351363, 2014.

[15] M. Shinozuka, M. Q. Feng, H.-K. Kim, and S.-H. Kim, "Nonlinear static procedure for fragility curve development," Journal of Engineering Mechanics, vol. 126, no. 12, pp. 1287-1295, 2000.

[16] N. I. Basoz, A. S. Kiremidjian, S. A. King, and K. H. Law, "Statistical analysis of bridge damage data from the 1994 Northridge, CA, Earthquake," Earthquake Spectra, vol. 15, no. 1, pp. 25-54, 1999.

[17] J. E. Padgett and R. DesRoches, "Methodology for the development of analytical fragility curves for retrofitted bridges," Earthquake Engineering and Structural Dynamics, vol. 37, no. 8, pp. 1157-1174, 2008.

[18] W. Yuan, B. Wang, P. Cheung, X. Cao, and Z. Rong, "Seismic performance of cable-sliding friction bearing system for isolated bridges," Journal of Earthquake Engineering and Engineering Vibration, vol. 11, no. 2, pp. 173-183, 2012.

[19] Ministry of Transport, Guidelines for Seismic Design of Highway Bridges, China Communication Press, Beijing, China.

[20] M. A. Hariri-Ardebili, S. Sattar, and H. E. Estekanchi, "Performance-based seismic assessment of steel frames using endurance time analysis," Engineering Structures, vol. 69, pp. 216-234, 2014.

[21] H. W. Lilliefors, "On the Kolmogorov-Smirnov test for normality with mean and variance unknown," Journal of the American Statistical Association, vol. 62, no. 318, pp. 399-402, 1967. 


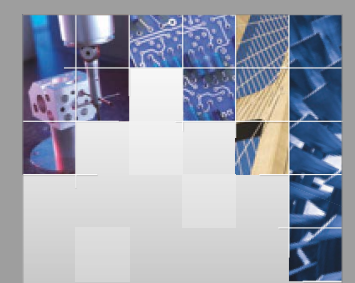

\section{Enfincering}
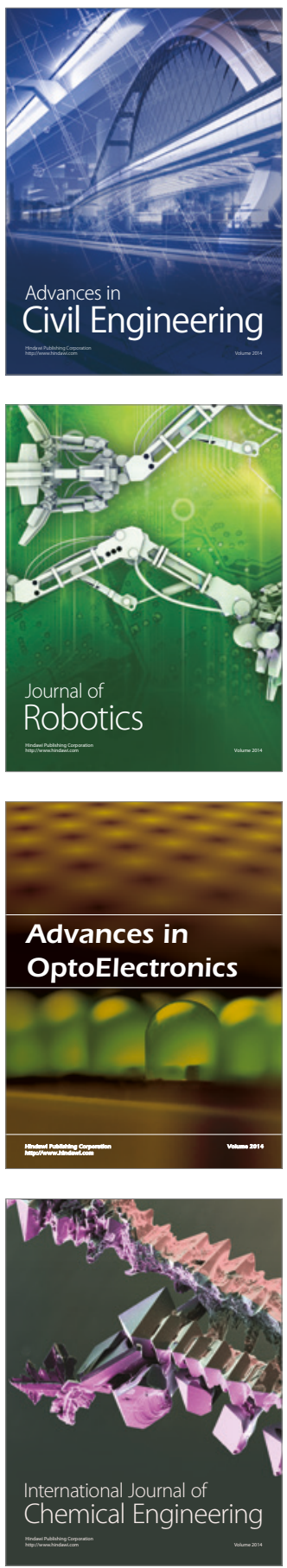

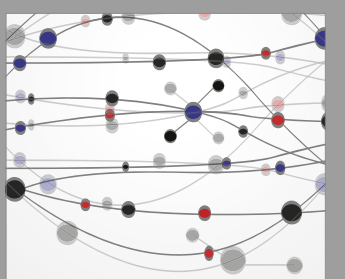

The Scientific World Journal

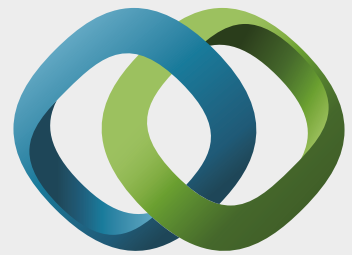

\section{Hindawi}

Submit your manuscripts at

https://www.hindawi.com
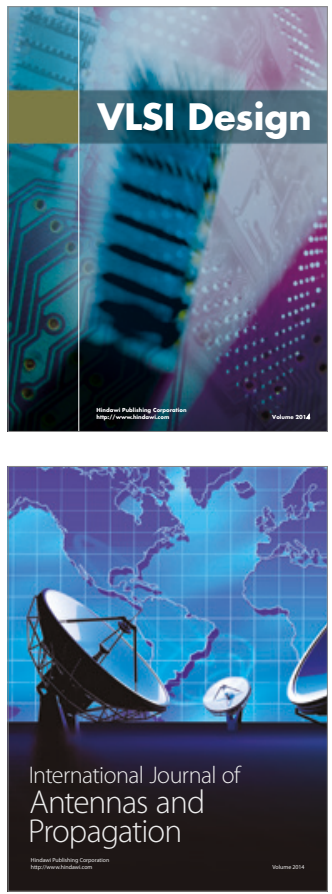

\section{Rotating}

Machinery
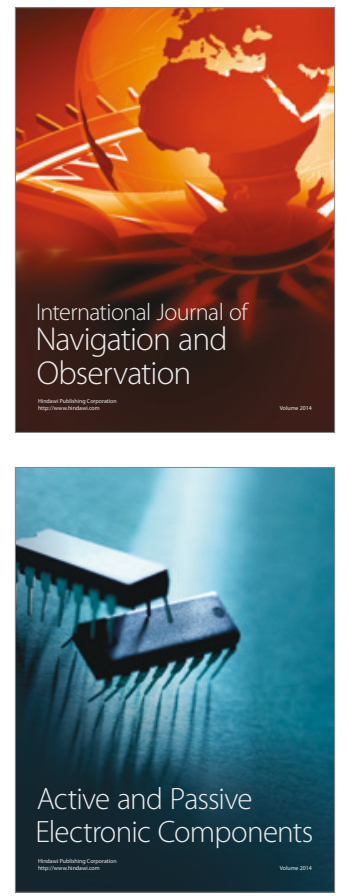
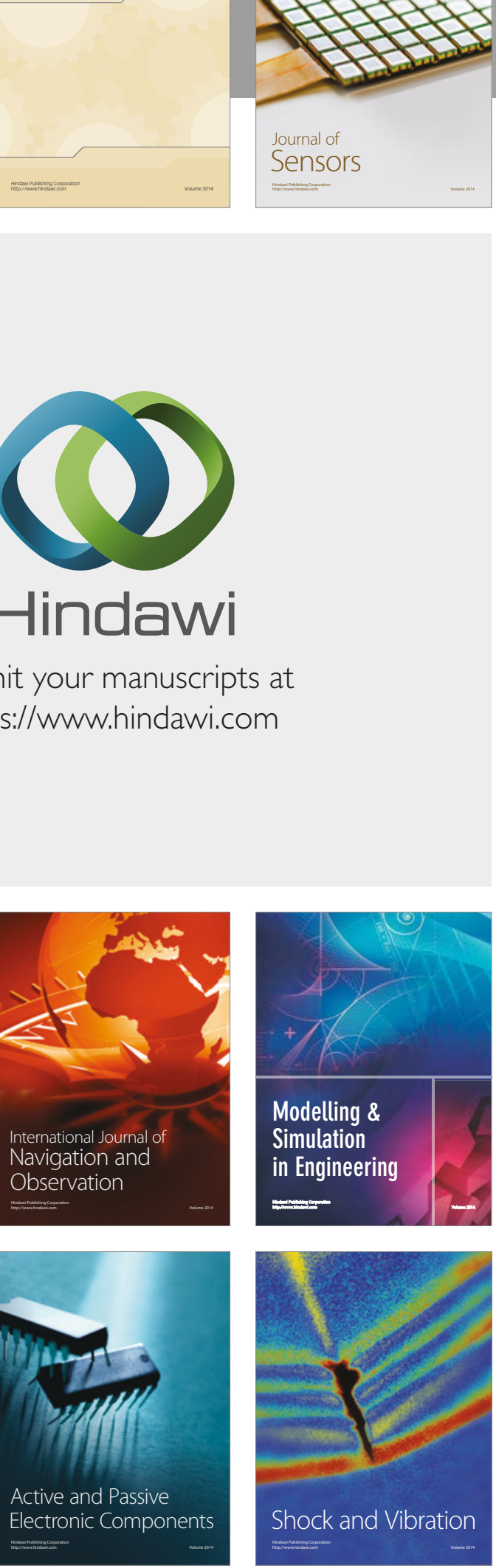
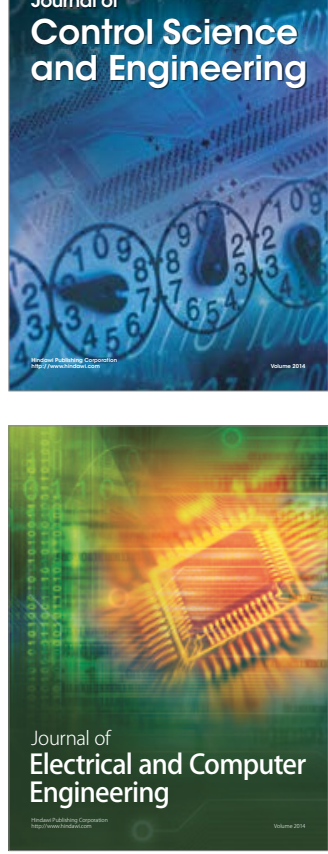

Distributed

Journal of

Control Science

and Engineering
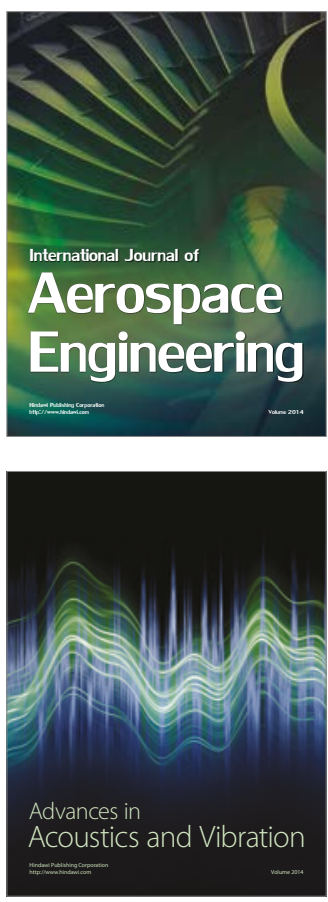

Sensor Networks 